\title{
Y-27632 is associated with corticosteroid- potentiated control of pulmonary remodeling and inflammation in guinea pigs with chronic allergic inflammation
}

Patricia Angeli Pigati ${ }^{1 *}$, Renato Fraga Righetti ${ }^{1}$, Samantha Souza Possa ${ }^{1}$, Beatriz Saraiva Romanholo ${ }^{3,4,5}$,

Adriana Palmeira Dias Rodrigues ${ }^{1}$, Anelize Sartori Alves dos Santos ${ }^{1}$, Débora Gonçalves Xisto²,

Mariana Alves Antunes ${ }^{2}$, Carla Máximo Prado ${ }^{1}$, Edna Aparecida Leick ${ }^{1}$, Milton de Arruda Martins ${ }^{1}$,

Patrícia Rieken Macedo Rocco ${ }^{2}$ and Iolanda de Fátima Lopes Calvo Tibério ${ }^{1}$

\begin{abstract}
Background: Previously, we showed that treatment with the Rho-kinase inhibitor Y-27632 was able to control airway responsiveness, inflammation, remodeling, and oxidative stress in an animal model of asthma, suggesting that this drug is beneficial in asthma. However, studies evaluating the effects of these inhibitors in conjunction with corticosteroids on chronic pulmonary inflammation have not been conducted. Therefore, we evaluated the effects of treatment with the Rho-kinase inhibitor Y-27632, with or without concurrent dexamethasone treatment, on airway and lung tissue mechanical responses, inflammation, extracellular matrix remodeling, and oxidative stress in guinea pigs with chronic allergic inflammation.

Methods: The guinea pigs were subjected to seven ovalbumin or saline inhalation exposures. Treatment with Y-27632 (1 mM) and dexamethasone $(2 \mathrm{mg} / \mathrm{kg})$ started at the fifth inhalation. Seventy-two hours after the seventh inhalation, the pulmonary mechanics were evaluated and exhaled nitric oxide ( $E_{N O}$ ) levels were determined. The lungs were removed and histological analysis was performed using morphometry.

Results: The treatment of guinea pigs with the Rho-kinase inhibitor and dexamethasone (ORC group) decreased $\mathrm{E}_{\mathrm{NO}}$, the maximal mechanical responses after antigen challenge, inflammation, extracellular matrix remodeling and oxidative stress in the lungs.

This therapeutic strategy reduced the levels of collagen and IFN- $\gamma$ in the airway walls, as well as IL-2, IFN- $\gamma$, 8-iso-PGF2a and NF-KB in the distal parenchyma, when compared to isolated treatment with corticosteroid or Rho-kinase inhibitor $(P<0.05)$ and reduced the number of TIMP-1-positive cells and eosinophils in the alveolar septa compared to corticosteroid-treated animals $(P<0.05)$. The combined treatment with the Rho-kinase inhibitor and the corticosteroid provided maximal control over the remodeling response and inflammation in the airways and parenchyma.
\end{abstract}

Conclusions: Rho-kinase inhibition, alone or in combination with corticosteroids, can be considered a future pharmacological tool for the control of asthma.

Keywords: Rho-kinase, Corticosteroid, Asthma model, Y-27632, Airways, Lung mechanics, Guinea pigs

\footnotetext{
*Correspondence: pangelipigati@gmail.com

'Department of Medicine, School of Medicine, University of São Paulo, São

Paulo, Brazil

Full list of author information is available at the end of the article
} 


\section{Background}

Asthma is a complex chronic respiratory disease that depends on the interaction of genetic and environmental factors [9], and it features the activation of Th2 cells. Studies in humans and in animal asthma models have shown that inflammation, obstruction, and remodeling occur not only in the proximal airways but also in the distal pulmonary parenchyma $[1,5,49]$. The impairment of the distal airways is recognized as an important factor contributing to airflow obstruction [23], particularly in patients with severe asthma and nocturnal asthma [7].

The remodeling response in asthmatics contributes to significant changes in the structures of the proximal and distal airways [40], as well as in the extent of airflow obstruction. This process involves airway smooth muscle hypertrophy and hyperplasia, mucous gland hyperplasia, and an increase in the thickness of the airway wall [4]. Currently, anti-inflammatory therapies, such as corticosteroids, are considered the gold-standard treatment for asthma, particularly during an acute asthma attack. Corticosteroids inhibit numerous pro-inflammatory responses and induce numerous anti-inflammatory pathways. However, the development of new drugs that control this disease is essential for patients with severe, corticosteroidinsensitive asthma [18] and to decrease the collateral systemic effects of steroid use.

Under physiologic conditions, smooth muscle contraction is controlled by the phosphorylation of the myosin light chains [35] via Rho-mediated $\mathrm{Ca}^{2+}$ sensitization [45], or by myosin phosphatase activity, which dephosphorylates the myosin light chains [15] independently of the cytoplasmic calcium concentration [21].

The inhibition of Rho/Rho-kinase pathway may be considered a potential pharmacological and therapeutic target in lung diseases [47] because it relaxes the airway smooth muscle tone and decreases airway inflammation and remodeling. These various functions are associated with changes in the actin cytoskeleton, including cell adhesion, motility, migration, and contraction [50]. The increased activity of Rho-kinase in the vascular smooth muscle under pathophysiological conditions has been reported in hypertensive animal models [33] and in humans [26]. Thus, inhibitors of Rho/Rho-kinase that relax the airway smooth muscle and reduce muscle tone are predicted to be relevant to asthma treatment $[6,12]$.

Recently, our research group published promising results using the Rho-kinase inhibitor Y-27632 in an animal model of chronic allergic inflammation. Treatment with Y-27632 (a pyridine derivative, (+)-(R)-trans-4(1-aminoethyl)-N-(4-pyridyl) cyclohexane carboxamide), a selective inhibitor of Rho-kinase family enzymes, in sensitized animals reduced lung mechanics, inflammation, remodeling and oxidative stress in the airway and lung tissue [36, 41].
Considering the relevance of corticosteroids as the gold standard treatment for asthma and aiming to complement our previous research, the focus of the present study was to evaluate the importance of combining a new class of drugs for controlling bronchial smooth muscle contraction with a corticosteroid. Knowing that the peripheral lung tissue is involved in asthma physiopathology, especially in severely asthmatic patients [13], we decided to broaden our research focus to not only include the evaluation of the airways but also study the lung parenchyma. We believe that this approach differentiates our study from those previously conducted by comprehensively covering two different compartments that determine the pathogenesis of this disease.

\section{Methods}

\section{Animals}

The animals weighed approximately 300-350 g initially and were approximately 3 weeks old. All guinea pigs were humanely cared for during all experimental procedures and in full compliance with the "Guide for care and use of laboratory animals" (NIH publication 85-23, revised 1985). All of the experiments described in this study were supervised and approved by the Institutional Review Board of the University of São Paulo (São Paulo, Brazil).

\section{The experimental model of pulmonary allergic inflammation}

Chronic airway inflammation was induced as previously described $[1,24,25]$. The guinea pigs were individually placed in plexiglass boxes $(30 \times 15 \times 20 \mathrm{~cm})$ coupled to an ultrasonic nebulizer (Soniclear, São Paulo, Brazil), and an aerosol of ovalbumin solution (Grade V, Sigma Chemical Co., Saint Louis, MO) diluted in $0.9 \% \mathrm{NaCl}$ sterile saline solution was generated for $15 \mathrm{~min}$ or until respiratory distress occurred. This protocol consists of a total of seven inhalation exposures. The exposures were performed twice a week for four weeks, with increasing concentrations of ovalbumin $(1-5 \mathrm{mg} / \mathrm{mL})$ to avoid tolerance (Fig. 1). For inhalations 1 to 4 (first two weeks), the dose of ovalbumin used was $1.0 \mathrm{mg} / \mathrm{mL}$. On the fifth and sixth inhalations, animals received a solution with $2.5 \mathrm{mg} / \mathrm{mL}$ of ovalbumin, and for the seventh inhalation, the dose was increased to $5.0 \mathrm{mg} / \mathrm{mL}$. The control animals received aerosolized saline [51].

\section{Treatment with Rho-kinase inhibitor}

From the fifth inhalation of the experimental protocol onward, the guinea pigs were exposed for $2 \mathrm{~min}$ by inhalation to $1 \mathrm{mM} \mathrm{Y-27632}$ for $10 \mathrm{~min}$ before each ovalbumin or normal saline exposure, as described in a previous study [17]. The authors of that study verified that a 2 min inhalation exposure with $1 \mathrm{mM}$ of Y-27632 inhibited acetylcholine-induced increases in 


\section{Protocol of chronic pulmonary allergic inflammation}

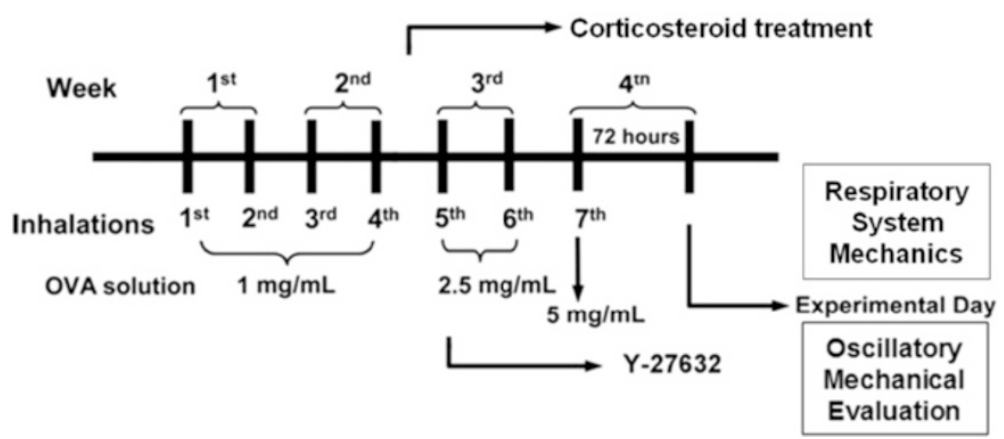

Fig. 1 Timeline of the experimental protocol. The guinea pigs received 7 inhalation exposures (2 per week over 4 weeks) with aerosols of saline (SAL group) or ovalbumin solution (OVA group) containing an increasing dose of the antigen. From the 1st to the 4th exposures, the animals received $1 \mathrm{mg} / \mathrm{mL}$ ovalbumin (first two weeks). In the 5th and 6th exposures (third week), the animals received $2.5 \mathrm{mg} / \mathrm{mL}$ ovalbumin, and in the 7th exposure (beginning of the fourth week), a dose of $5 \mathrm{mg} / \mathrm{mL}$ of antigen was used. The solution of ovalbumin or saline was continuously aerosolized for either $15 \mathrm{~min}$ or until respiratory distress occurred. After the 5th exposure, the guinea pigs in the Rho-kinase inhibitor group received Y-27632 (1 mM; $2 \mathrm{~min}$ ) by inhalation (OVA-RHO group) and/or dexamethasone (2 mg/kg-1/day i.p.) (OVA-C groups or ORC groups) 10 min before each exposure to OVA or SAL until the end of the experimental protocol. Seventy-two hours following the seventh exposure, the animals were anesthetized and exsanguinated, the exhaled nitric oxide was collected, and the mechanics of the respiratory system (Ers and Rrs) and the oscillatory parameters of the distal lung tissue (Et and Rt) were evaluated under basal conditions and after challenge with OVA (0.1\%). Afterwards, lung slices were removed and submitted to histopathological evaluation

lung resistance without altering the mean blood pressure. They performed acetylcholine exposures $10 \mathrm{~min}$ after inhalation of Y-27632 and verified that $1 \mathrm{~h}$ later, the drug was already affecting lung resistance. We did not give a higher concentration of Y-27632 by intravenous injection because it can decrease the mean blood pressure, as shown in hypertensive rats [52]. In our study, on the day of the mechanical evaluation, the Y-27632 inhalation exposure was performed $1 \mathrm{~h}$ before the start of the experiment. We opted to administer the drug via inhalation because of the direct effect on the respiratory system and to minimize systemic effects.

\section{Corticosteroid treatment}

To avoid interference with the OVA sensitization, immediately before the fifth inhalation the guinea pigs received dexamethasone $(2 \mathrm{mg} / . \mathrm{kg}-1 /$ day i.p.) five hours before ovalbumin or saline inhalation until the end of the experimental protocol. In a previous study, using the passive cutaneous anaphylaxis technique (PCA), we observed an increase in specific IgG1 homocytotropic anaphylactic antibodies in guinea pigs that received four inhalation exposures with ovalbumin at the end of the second week of the PCA protocol $[25,44]$.

\section{Experimental groups}

Five groups of guinea pigs were studied:

A) animals that received normal saline (SAL, $\mathrm{n}=8)$;

B) animals that received ovalbumin (OVA, $\mathrm{n}=8$ );
C) animals that received ovalbumin and Y-27632 after the fifth inhalation exposure (OVA-RHO group, $\mathrm{n}=8$ );

D) animals that received ovalbumin and corticosteroids (OVA-C group, $\mathrm{n}=8$ );

E) animals that received ovalbumin, Y-27632 after the fifth inhalation, and corticosteroid treatment (ORC group, $\mathrm{n}=8$ ).

The experiment was performed in duplicate to evaluate the oscillatory distal lung mechanics.

\section{Measurement of $\mathrm{E}_{\mathrm{NO}}$}

Seventy-two hours after the last inhalation exposure, the guinea pigs were anesthetized with pentobarbital sodium (50 mg/kg, intraperitoneal injection), a tracheotomy was performed and the animals were mechanically ventilated at 60 breaths $/ \mathrm{min}$ with a tidal volume of $8 \mathrm{~mL} / \mathrm{kg}$ using a Harvard 683 ventilator (Harvard Apparatus, USA). After that, the exhaled nitric oxide $\left(\mathrm{E}_{\mathrm{NO}}\right)$ level was measured as previously described $[25,37]$. Briefly, to obtain the $\mathrm{E}_{\mathrm{NO}}$ levels after stabilization of the animal on the ventilator, a collection bag was attached to the expiratory output of the ventilator and exhaled air was collected for $3 \mathrm{~min}$. $\mathrm{E}_{\mathrm{NO}}$ was measured by a chemiluminescence technique using a fast-responding analyzer (NOA 280; Sievers Instruments, Boulder, CO). The analyzer was calibrated with a certified 47 parts per billion (ppb) NO source (White Martins, São Paulo, Brazil) and zero nitric oxide (NO) filter (Sievers Instruments) before each measurement. The NO filter 
was attached to the inspiratory input to avoid environmental contamination.

\section{Pulmonary mechanics evaluation Respiratory system mechanics}

After the $\mathrm{E}_{\mathrm{NO}}$ measurement, mechanical evaluation was conducted. The tracheal pressure (Ptr) was measured using a 142PC05D differential pressure transducer (Honeywell, Freeport, IL) connected to a side tap in the tracheal cannula. Airflow ( $\left.\mathrm{V}^{\prime}\right)$ was obtained using a pneumotachograph (Fleish-4-0, Richmond, VA) connected to the tracheal cannula and to a Honeywell 163PC01D36 differential pressure transducer. Lung volume $(\mathrm{V})$ changes were determined by digital integration of the airflow signal. Nine to ten respiratory cycles were averaged to provide one data point. The Ptr, V', and V signals were collected before and after the SAL or OVA challenge and were stored in a microcomputer [37, 44, 51]. The baseline measurements of Ptr and V' were performed after stabilization of the animal on the ventilator. Afterwards, the animals were exposed to $2 \mathrm{~min}$ of inhalation of either an aerosol of ovalbumin $(30 \mathrm{mg} / \mathrm{mL}$, given to the OVA and OVA-RHO groups) or normal saline (given to the SAL groups) delivered into the inspiratory circuit through the air inlet of the ventilator. Measurements of the Ptr and V' were taken 1 and $3 \mathrm{~min}$ after the beginning of the first OVA/SAL challenge. Respiratory system elastance (Ers) and resistance (Rrs) were obtained using the equation of motion of the respiratory system: $\operatorname{Ptr}(\mathrm{t})=\mathrm{Ers} \cdot \mathrm{V}(\mathrm{t})+\operatorname{Rrs} \cdot \mathrm{V}^{\prime}(\mathrm{t})$, where $\mathrm{t}$ represents time. Immediately after the end of the mechanical evaluation, a positive end-expiratory pressure of $5 \mathrm{cmH}_{2} \mathrm{O}$ was applied and the trachea was occluded with a 5.0 silk suture at the end of the expiration to maintain lung inflation. Then, the guinea pigs were exsanguinated via the abdominal aorta, the anterior chest wall was removed, and the lungs were removed en bloc. The removed lungs were fixed with buffered $10 \%$ paraformaldehyde for $24 \mathrm{~h}$ and then transferred to $70 \%$ ethanol to prepare histological slides for morphometric analysis.

\section{Lung oscillatory mechanics}

After the last inhalation exposure (72 h), the animals were anaesthetized with pentobarbital sodium $(50 \mathrm{mg} / \mathrm{kg})$ and a tracheotomy was performed. Afterwards, the thorax was opened and the animals were exsanguinated. The lungs were removed en bloc and placed in a modified KrebsHenseleit (K-H) solution (containing, in mM: $118.4 \mathrm{NaCl}$, $4.7 \mathrm{KCl}, 1.2 \mathrm{~K}_{3} \mathrm{PO}_{4}, 25 \mathrm{NaHCO}_{3}, 2.5 \mathrm{CaCl}_{2} \cdot \mathrm{H}_{2} \mathrm{O}$, $0.6 \mathrm{MgSO}_{4} \cdot \mathrm{H}_{2} \mathrm{O}$, and 11.1 glucose) at $\mathrm{pH}=7.40$ and $6{ }^{\circ} \mathrm{C}$ (63). Strips $(2 \times 2 \times 10 \mathrm{~mm})$ were cut from the periphery of the left lung and suspended vertically in a $\mathrm{K}-\mathrm{H}$ organ bath that was maintained at $37{ }^{\circ} \mathrm{C}$ and continuously bubbled with a mixture of $95 \% \mathrm{O}_{2}-5 \% \mathrm{CO}_{2}$. The lung strips were weighed, and their unloaded resting lengths $\left(L_{0}\right)$ were determined using a caliper. The lung strip volume was measured by simple densitometry and calculated as: volume $=\Delta \mathrm{F} / \delta$, where $\Delta \mathrm{F}$ is the total change in force before and after immersion of the strip in $\mathrm{K}-\mathrm{H}$ solution, and $\delta$ is the mass density of $\mathrm{K}-\mathrm{H}$ solution [34]. Parenchymal strips were suspended vertically in a $\mathrm{K}-\mathrm{H}$ organ bath (30 mL internal volume) that was maintained at $37^{\circ} \mathrm{C}$ and continuously bubbled with $95 \% \mathrm{O}_{2}-5 \% \mathrm{CO}_{2}$, as previously described [43]. Briefly, one end of the strip was attached to a force transducer (LETICA TRI-110; Scientific Instruments, Barcelona, Spain) and the other was fastened to a lever arm actuated by means of a modified woofer, driven by a computer-generated signal and digitally converted (AT-MIO-16-E-10, National Instruments, Austin, TX). A sidearm of this rod was linked to a second force transducer (LETICA TRI-110; Scientific Instruments) by means of a silver spring of a known Young's modulus, thus allowing for the measurement of displacement. Neither amplitude dependence $(<0.1 \%$ change in stiffness) nor phase changes with frequency were detected in the 0.01 - to $14-\mathrm{Hz}$ range. The hysteresivity of the system $(<0.003)$ was frequency-independent.

A cross-sectional, unstressed area $\left(A_{0}\right)$ of the strip was identified from the volume and the unstressed length as calculated according to $A_{0}=\mathrm{vol} / L_{0}$. The basal force $\left(\mathrm{F}_{\mathrm{B}}\right)$ for a stress of $0.1 \mathrm{~N} / \mathrm{cm}^{2}$ was calculated as $\mathrm{F}_{\mathrm{B}}(\mathrm{N})=10$ $\left(\mathrm{N} / \mathrm{cm}^{2}\right) \times A_{0}\left(\mathrm{~cm}^{2}\right)$ and adjusted by vertical displacement of the force transducer, as previously described [25]. The displacement signal was then set to zero. Once the basal force and displacement signals were adjusted, the length between bindings $\left(L_{\mathrm{B}}\right)$ was measured using a precision caliper. The instantaneous length during oscillation around $L_{\mathrm{B}}$ was determined by adding the value of $L_{\mathrm{B}}$ to the measured value of displacement at any given time. The instantaneous average cross-section area $\left(A_{\mathrm{i}}\right)$ was determined as $A_{\mathrm{i}}=\mathrm{vol} / L_{\mathrm{i}}\left(\mathrm{cm}^{2}\right)$, where $L_{\mathrm{i}}$ is the instantaneous length.

The instantaneous stress $\left(\sigma_{\mathrm{i}}\right)$ was calculated by dividing force $(\mathrm{F}$; in $\mathrm{g})$ by $A \mathrm{i}\left(\mathrm{cm}^{2}\right)$ using the equation $\sigma_{\mathrm{i}}=\mathrm{F} / A_{\mathrm{i}}$. The strain was calculated as $\Delta \varepsilon=\left(L-L_{\mathrm{B}}\right) / L_{\mathrm{B}}$. After the basal force was adjusted to $0.5 \times 10^{-2} \mathrm{~N}$, each parenchymal strip was preconditioned by sinusoidal oscillation of the tissue for $30 \mathrm{~min}$ (frequency $=1 \mathrm{~Hz}$, which is a large enough amplitude to reach a final force of $1 \times 10^{-2} \mathrm{~N}$ ). Thereafter, the amplitude was adjusted to $5 \% L_{0}$, and the oscillation was maintained for another $30 \mathrm{~min}$, or until a stable length-force loop was reached. The isometric stress adaptation period resulted in a final force of $0.5 \times 10^{-2} \mathrm{~N}$. After preconditioning, the strips were oscillated at a frequency $(f)$ of $1 \mathrm{~Hz}$ [42] and with a constant force of $0.5 \times 10^{-2} \mathrm{~N}$. The bath solution was renewed every 20 min with $37{ }^{\circ} \mathrm{C} \mathrm{K}-\mathrm{H}$ solution. 
All mechanical parameters were measured cycle by cycle. The tissue resistance (Rt) was determined from the enclosed area of force length loops: $\mathrm{R}=(4 \times H) /[\pi \times \omega \times$ $\left.(\Delta \varepsilon)^{2}\right]$, where $H$ is the stress-strain hysteresis area, $\omega$ is the angular frequency $[\omega=2 \pi f(\mathrm{rad} / \mathrm{s})$, where $f$ is the frequency], and $\Delta \varepsilon$ is the normalized strain or peak-to-peak change in the length divided by $L_{\mathrm{B}}$. The tissue dynamic $\mathrm{E}$ was determined as: $\mathrm{Et}=(\Delta \sigma \mathrm{l} / \Delta \varepsilon) \cos \theta$, where $\Delta \sigma \mathrm{l}$ is the peak-to-peak change in force, and $\theta$ is the phase lag between force and displacement $\left[\left(\theta=\sin ^{-1}\{4 \times H /[\pi(\Delta \sigma \mathrm{\iota} \times\right.\right.$ $\Delta \varepsilon)\})]$. The $\eta$, which is an empirically determined variable that quantifies the dependence of dissipative processes on elastic processes, was calculated as $\eta=\tan \theta$. The tissue resistance $(\mathrm{Rt})$, elastance $(\mathrm{Et})$, and hysteresivity $(\eta)$ were calculated for the baseline condition and after ovalbumin challenge (dose of $0.1 \%$ of ovalbumin) [8].

The lung strips were fixed with buffered $10 \%$ paraformaldehyde for $24 \mathrm{~h}$ and then transferred to $70 \%$ ethanol to prepare histological slides for morphometric analysis.

\section{Morphometric analysis}

The homogeneity of the strip samples was assured by measuring the fractional area of the tissue constituents using the point-counting method $[1,34,53]$ and a 100 point grid with a known area $\left(62,500 \mu \mathrm{m}^{2}\right.$ at $400 \times$ magnification) attached to the ocular of the microscope. We measured the fractional area of the bronchial wall (BW), the blood vessel wall (BVW), and the alveolar wall (AW) as the number of points that fell within BW, BVW or AW divided by the total number of points that fell within the strip tissue. The measurements were performed in 10 fields per slide at $400 \times$ magnification. We calculated the mean values for each animal.

All morphometric evaluations were performed by a blind analysis. The histologic slides were not named with the names of the groups and the researcher had no knowledge of the procedures for each group.

\section{Evaluation of eosinophils}

Lung strips that were $5 \mu \mathrm{m}$ thick were stained with LUNA for eosinophil evaluation [1, 41, 49]. The percentage of eosinophils in the lung parenchyma and the airway was evaluated through morphometric analysis using a reticule of known area (50 lines and 100 dots) and a microscope (CH30, Olympus, Japan). Positive cells were quantified at a magnification of $1000 \times$ using the ratio of points identifying such cells in a known area to the total number of points within the lung tissue and airway. The results are expressed in cells per unit area $\left(10^{4} \mu \mathrm{m}^{2}\right)$. The quantification was performed in 10 random fields in the distal lung and three fields of the airway wall, from 3-5 airways per animal. Several authors have previously demonstrated that this method is adequate and reproducible [25, 36].

\section{Picro-Sirius and Resorcin-Fuchsin staining}

Picro-Sirius staining was used to quantify collagen fibers and Resorcin-Fuchsin staining was used to identify elastic fibers in the airways and lung tissue. The volume fraction of collagen and elastic fibers in the airways and the alveolar tissue of the lung strips was determined (10 fields and 3-5 airways, $400 \times$ ) by dividing the number of points contained within collagen or elastic fibers by the total number of points within the airway and lung tissue. The results are expressed as percentages $[37,38]$.

\section{Immunohistochemical evaluation}

Immunohistochemical evaluation was performed using the following dilutions of primary antibodies: 1:400 (IL-2 - cod. sc- 7896), 1:500 (IL-4 - cod. sc-1260), 1:200 (IL-5 - cod. sc-7887), 1:200 (IL-13 - cod. 1776), 1:150 (IFN- $\gamma-$ cod. sc-8308), 1:150 (NF-kB - cod. sc-109), 1:250 (MMP-9 - cod. sc-6840), 1:250 (TIMP-1 - cod. sc-5538), 1:1500 (TGF- $\beta$ - cod. sc-146), all from Santa Cruz Biotechnology, Santa Cruz, CA. The anti-8-iso-prostaglandin F (PGF) $2 \alpha$ antibody (Oxford Biomedical Research, Rochester Hills, MI - cod. IS20) was used at a 1:500 dilution and the anti-iNOS antibody (BD Transduction Laboratories, San Diego, CA, USA, cod. N32020) was used at a 1:250 dilution. The following sequence of procedures was used to stain the samples: antigenic recovery, blockage and incubation with primary antibody, incubation with secondary antibody complex, staining and counterstaining. The slides were prepared and counts were performed in 10 random fields per sample, as described above for the evaluation of eosinophils.

\section{Passive cutaneous anaphylaxis reaction}

To evaluate whether Rho-kinase inhibitor and/or corticosteroid treatment interfered with sensitization to ovalbumin, we measured the production of IgE and IgG1 antibodies to ovalbumin by passive cutaneous anaphylaxis (PCA), as previously described [32]. Three guinea pigs from each experimental group were anesthetized with pentobarbital sodium (50 mg/kg i.p.) on day 26 and $5 \mathrm{~mL}$ of blood were collected by cardiac puncture. Antibody titers were estimated by determining the highest dilution of antiserum that induced a PCA reaction. It is important to clarify that this procedure was performed one week after the seventh inhalation.

\section{Statistical analysis}

All statistical analyses were performed using the SigmaStat software (SPSS Inc., USA). All data represent the means \pm standard error (S.E.). The statistical significance of the differences between groups was determined using a One-Way Analysis Of Variance (ANOVA) followed by the Holm-Sidak method for multiple comparisons. We 
also obtained the Pearson correlation coefficient $(R)$ to assess the associations of the pulmonary mechanical scores with the markers for inflammation, remodeling and oxidative stress. Differences were considered significant when $\mathrm{P}<0.05$.

\section{Results}

\section{Inhalation time}

There were no differences in the inhalation time among the groups studied until the fourth inhalation, and all of the animals reached $900 \mathrm{~s}$ of inhalation (Fig. 2). None of the animals in the normal saline group presented with respiratory distress during the seven inhalation exposures. From the fifth to the seventh inhalation, sensitized and non-treated animals (OVA group) presented lower inhalation times compared to the groups sensitized and treated with Y-27632, the corticosteroid or Y-27632 and the corticosteroid (OVA-RHO, OVA-C and ORC groups, respectively; $\mathrm{P}<0.05)$. There was a significant difference between the OVA-RHO and OVA-C groups $(\mathrm{P}<0.05)$.

\section{Exhaled nitric oxide}

The concentrations of $\mathrm{E}_{\mathrm{NO}}$ were higher in the OVA group than in the SAL group $(\mathrm{P}<0.001)$. However, treatment with Y-27632, the corticosteroid or Y-27632 and the corticosteroid reduced the level of $\mathrm{E}_{\mathrm{NO}}$ compared with the OVA group $(\mathrm{P}<0.05)$. There were no significance differences among the OVA-RHO, OVA-C and ORC groups (Fig. 3).

\section{Mechanical evaluation}

\section{Measurements of respiratory system mechanics}

Compared to the baseline values of Rrs and Ers, there were no differences among the groups (data not shown). The percentage of the maximal increase in airway Rrs is shown in Fig. 4a. There was a significant increase in the

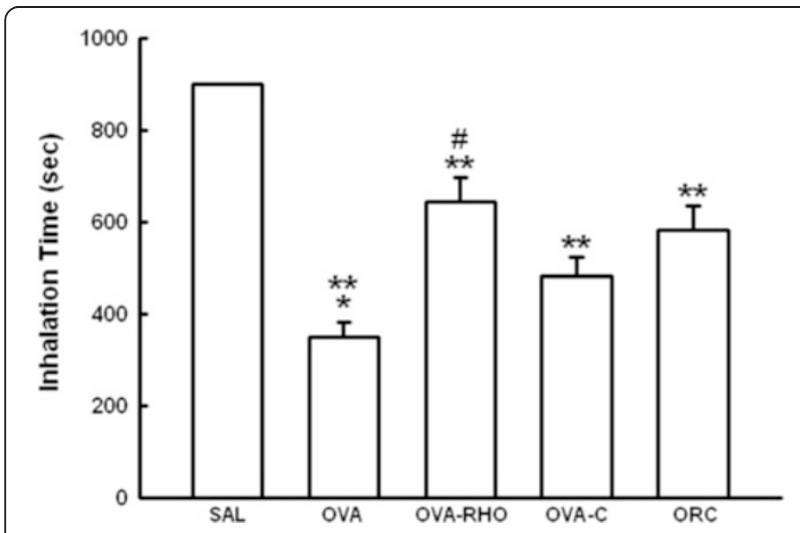

Fig. 2 Vertical bar graph showing the mean \pm SEM of the inhalation time. ${ }^{*} \mathrm{P}<0.05$, compared with the OVA-RHO, OVA-C and ORC groups. ${ }^{* *} \mathrm{P}<0.001$, compared with the $\mathrm{SAL}$ group. ${ }^{*} \mathrm{P}<0.05$, compared with the OVA-C group

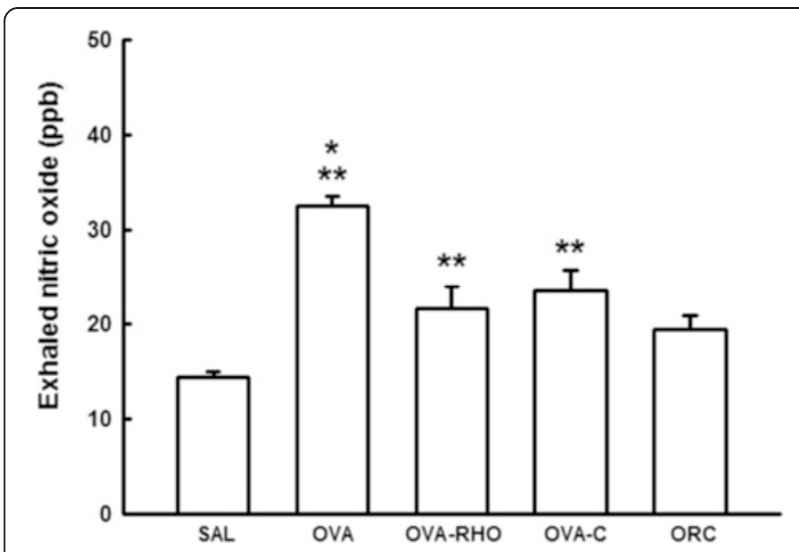

Fig. 3 Vertical bar graph representing the mean \pm SEM of the $E_{N O}$ concentrations of the anesthetized guinea pigs. The $\mathrm{E}_{\mathrm{NO}}$ was collected $72 \mathrm{~h}$ after the 7 th exposure (before the challenge) to saline or OVA solutions in the 5 experimental groups. ${ }^{*} \mathrm{P}<0.05$, compared with the OVA-RHO, OVA-C and ORC groups. ${ }^{* *} \mathrm{P}<0.05$, compared with the SAL group

\%Rrs of the OVA group compared to the control (SAL group, $\mathrm{P}<0.001)$. The treatment of sensitized animals with the Rho-kinase inhibitor, the corticosteroid or both the Rho-kinase inhibitor and the corticosteroid attenuated this response (OVA-RHO, OVA-C and ORC groups, respectively) compared with the OVA group $(\mathrm{P}<0.001)$.

The percentage of the maximal increase in airway Ers is shown in Fig. 4b. There was a significant increase in the \%Ers of the OVA group compared to the control (SAL group, $\mathrm{P}<0.001$ ). The treatment of the sensitized animals with the Rho-kinase inhibitor, the corticosteroid or both the Rho-kinase inhibitor and the corticosteroid (OVA-RHO, OVA-C and ORC groups, respectively) attenuated this response compared with the OVA group $(\mathrm{P}<0.001)$. There was no potentiation of this response in the ORC group.

\section{Measurements of lung tissue oscillatory mechanics}

Compared to the baseline values of $\mathrm{Rt}$ and Et, there were no differences among the groups (data not shown). The percentage of the maximal increase in airway $\mathrm{Rt}$ is shown in Fig. 4c. There was a significant increase in the $\%$ Rt of the OVA group compared to the control (SAL group, $\mathrm{P}<0.001)$. The treatment of the sensitized animals with the Rho-kinase inhibitor, the corticosteroid or both the Rho-kinase inhibitor and the corticosteroid (OVA-RHO, OVA-C and ORC groups, respectively) attenuated this response compared with the OVA group $(\mathrm{P}<0.05)$.

The percentage of the maximal increase in airway \%Et is shown in Fig. 4d. There was a significant increase in the \%Et of the OVA group compared to the control (SAL group, $\mathrm{P}<0.001$ ). The treatment of sensitized animals with the Rho-kinase inhibitor, the corticosteroid or 

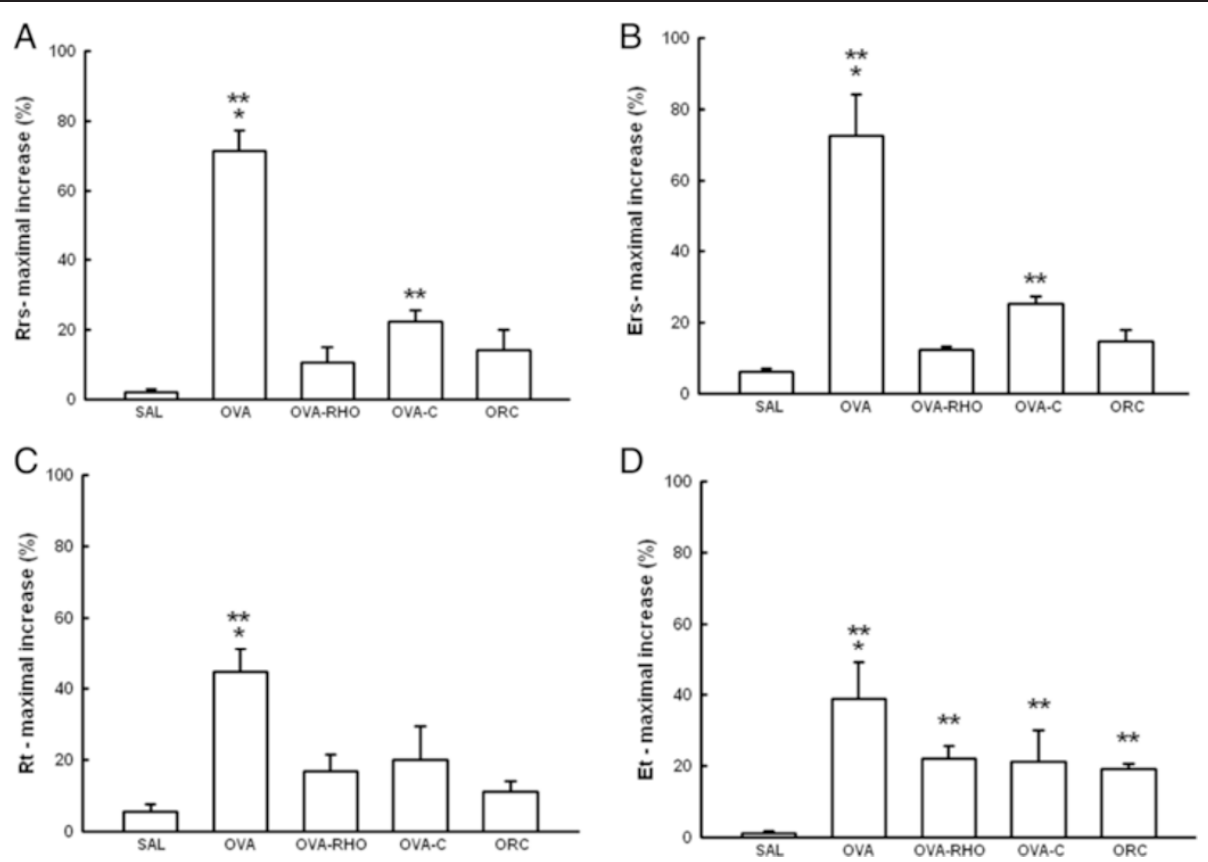

Fig. 4 The vertical bars graph shows the mean \pm SEM of the maximal percent increase in respiratory system resistance (Rrs) (a), respiratory system elastance (Ers) (b), lung tissue resistance (Rt) (c) and lung tissue elastance (Et) (d) obtained after airway and lung tissue challenge with ovalbumin or normal saline in anaesthetized guinea pigs. ${ }^{*} \mathrm{P}<0.001$, compared with the OVA-RHO, OVA-C and ORC groups. ${ }^{* *} \mathrm{P}<0.05$, compared with the SAL group

both the Rho-kinase inhibitor and the corticosteroid (OVA-RHO, OVA-C and ORC groups, respectively) attenuated this response compared with the OVA group $(\mathrm{P}<0.05)$.

There were no differences in the maximal responses in \%Et and \%Rt among the OVA-RHO, OVA-C and ORC groups.

\section{Morphometric analysis}

All of the groups showed a similar anatomical composition of the lung strips, with approximately $90 \%$ of the strip being the alveolar wall (SAL group: 93.2 \pm $1.10 \%$, OVA group: $92.3 \pm 0.76 \%$, OVA-RHO group: $92.6 \pm 1.29 \%$, OVA-C group: $93.4 \pm 0.85$ and ORC group: $98.0 \pm 0.68 \%)$.

\section{Effects on inflammation}

The absolute values for the number of eosinophils and the cellular inflammation markers, IFN- $\gamma$, IL-2, IL-4, IL-5 and IL-13, present in the four experimental groups are shown in Table 1 (airway and lung tissue).

In the airways and lung tissue, there was an increase in the eosinophil density in the OVA group compared with the SAL group $(\mathrm{P}<0.001)$. The OVA-RHO, OVA-C and ORC groups had a reduced eosinophil density in the airways and lung tissue compared with the OVA group $(\mathrm{P}<0.05)$. In the lung tissue of the OVA-RHO and ORC groups, there was a reduction in the eosinophil density compared with the OVA-C group, $(\mathrm{P}<0.05)$.

We observed an increase in IFN- $\gamma$-positive cells in the airways and lung tissue in the OVA group compared with the SAL group $(\mathrm{P}<0.001)$. The OVA-RHO, OVA-C and ORC groups had a reduced number of IFN- $\gamma-$ positive cells in the airways and lung tissue compared with the OVA group $(\mathrm{P}<0.001)$. There was a reduction in the number of IFN- $\gamma$-positive cells in the airways and lung tissue of the ORC group compared with the OVARHO and OVA-C groups $(\mathrm{P}<0.05)$.

There was an increase in the number of IL-2-positive cells in the airways and lung tissue from the OVA group compared with the SAL group $(\mathrm{P}<0.001)$. The OVARHO, OVA-C and ORC groups had a reduced numbers of IL-2-positive cells in the airways and lung tissue compared with the OVA group $(\mathrm{P}<0.001)$. Notably, there was also a significant decrease in the number of IL-2positive cells in the lung tissue from the ORC group compared to tissue from the OVA-RHO and OVA-C groups $(\mathrm{P}<0.05)$.

There was an increase in the number of IL-4-positive cells in the airways and lung tissue from the OVA group compared with the SAL group $(\mathrm{P}<0.001)$. The OVARHO, OVA-C and ORC groups had reduced numbers of IL-4-positive cells in the airways and lung tissue compared with the OVA group $(\mathrm{P}<0.001)$. 
Table 1 Absolute values of the morphometric analysis for inflammatory markers in the airway and lung tissue

\begin{tabular}{|c|c|c|c|c|c|}
\hline \multicolumn{6}{|l|}{ AIRWAY } \\
\hline BIOMARKERS & $\operatorname{SAL}(n=8)$ & OVA $(n=8)$ & OVA-RHO $(n=8)$ & OVA-C $(n=8)$ & ORC $(n=8)$ \\
\hline Eosinophils & $4.15 \pm 1.26$ & $33.56 \pm 4.66^{* * *}$ & $12.17 \pm 1.57 * / \#$ & $16.83 \pm 4.34$ * & $11.46 \pm 3.74 *$ \\
\hline IFN- $\gamma$ & $9.37 \pm 0.97$ & $35.36 \pm 2.50 * * *$ & $17.98 \pm 1.14^{+}$ & $18.02 \pm 0.83^{+}$ & $12.48 \pm 1.44^{+/ * *}$ \\
\hline IL-2 & $2.39 \pm 0.57$ & $32.76 \pm 6.95 * * *$ & $13.31 \pm 0.62^{+}$ & $12.47 \pm 0.97^{+}$ & $10.09 \pm 1.29^{+}$ \\
\hline $\mid \mathrm{L}-4$ & $4.69 \pm 0.68$ & $13.69 \pm 1.26 * * *$ & $6.34 \pm 1.58^{+}$ & $8.13 \pm 1.24^{+}$ & $5.61 \pm 0.85^{+}$ \\
\hline IL-5 & $4.53 \pm 0.75$ & $21.76 \pm 1.23$ *** & $11.43 \pm 1.74 *$ & $11.65 \pm 2.12 *$ & $9.67 \pm 1.34$ * \\
\hline $\mid \mathrm{L}-13$ & $1.19 \pm 0.75$ & $13.42 \pm 0.45^{* * *}$ & $4.37 \pm 1.12 *$ & $6.64 \pm 1.58 *$ & $4.59 \pm 0.68 *$ \\
\hline \multicolumn{6}{|l|}{ LUNG TISSUE } \\
\hline BIOMARKERS & $\operatorname{SAL}(n=8)$ & OVA $(n=8)$ & OVA-RHO $(n=8)$ & OVA-C $(n=8)$ & ORC $(n=8)$ \\
\hline Eosinophils & $0.75 \pm 0.27$ & $11.48 \pm 0.75^{* * *}$ & $4.13 \pm 0.15 * / \#$ & $6.15 \pm 2.19 *$ & $2.73 \pm 1.22 *$ \# \\
\hline IFN- $\gamma$ & $11.26 \pm 1.47$ & $25.48 \pm 1.13^{* * *}$ & $16.27 \pm 0.76^{+}$ & $19.08 \pm 0.61^{+}$ & $13.81 \pm 0.78^{+/ * *}$ \\
\hline IL-2 & $2.79 \pm 0.49$ & $19.53 \pm 1.39 * * *$ & $7.48 \pm 0.62^{+}$ & $9.26 \pm 0.45^{+}$ & $4.13 \pm 0.60^{+/ * *}$ \\
\hline $\mid \mathrm{L}-4$ & $2.57 \pm 0.37$ & $18.78 \pm 1.53^{* * *}$ & $11.26 \pm 0.92^{+}$ & $8.32 \pm 0.40^{+}$ & $6.89 \pm 0.96^{+}$ \\
\hline IL-5 & $2.25 \pm 0.54$ & $13.52 \pm 0.66^{* * *}$ & $5.76 \pm 0.47 *$ & $7.04 \pm 0.93 *$ & $5.90 \pm 1.00 *$ \\
\hline IL-13 & $1.38 \pm 0.59$ & $11.37 \pm 2.26$ *** & $4.74 \pm 1.32 *$ & $3.61 \pm 1.07 *$ & $2.62 \pm 0.76 *$ \\
\hline
\end{tabular}

The eosinophils, IFN- $\gamma$, IL-2, IL-4, IL-5, IL-13, are expressed in positive cells $/ 10^{4} \mu \mathrm{m}^{2}$. ${ }^{* * \mathrm{P}}<0.001$, compared with the SAL group; ${ }^{* \mathrm{P}}<0.05$, compared with the OVA group; ${ }^{\#} \mathrm{P}<0.05$, compared with the OVA-C group, ${ }^{+} \mathrm{P}<0.001$, compared with the OVA group, ${ }^{*}{ }^{*} \mathrm{P}<0.05$, compared with the OVA-RHO and OVA-C groups

There was an increase in the numbers of IL-5- and IL13-positive cells in the airways and lung tissue from the OVA group compared with the SAL group $(\mathrm{P}<0.001)$. The OVA-RHO, OVA-C and ORC groups had reduced numbers of IL-5- and IL-13-positive cells in the airways and lung tissue compared with the OVA group $(\mathrm{P}<0.05)$.

Figure 5 presents photomicrographs of the airway walls from guinea pigs in the experimental groups subjected to LUNA staining for the detection of eosinophil density and immunohistochemical staining for IFN- $\gamma$, IL-2, IL-4, IL-5 and IL-13 detection.

\section{Effects on extracellular matrix remodeling}

The absolute values of the remodeling markers for the volume fraction of collagen, elastic fibers and actin, TGF- $\beta$, MMP-9 and TIMP-1-positive cells in the four experimental groups are shown in Table 2 (airway and lung tissue).

We observed an increase in the volume fraction of collagen fibers in the airways and lung tissue from the OVA group compared to the SAL group $(\mathrm{P}<0.001)$. The OVA$\mathrm{RHO}, \mathrm{OVA}-\mathrm{C}$ and ORC groups showed a reduction in the volume fraction of collagen fibers in the airways and lung tissue compared to the OVA group $(\mathrm{P}<0.05)$. There was also a reduction of the volume fraction of collagen fibers in the airways of the ORC group compared to the OVARHO and OVA-C groups $(\mathrm{P}<0.05)$.

There was an increase in the volume fraction of elastic fibers and actin in the airways and lung tissue from the
OVA group compared with the SAL group $(\mathrm{P}<0.001)$. The OVA-RHO, OVA-C and ORC groups had a reduced volume fraction of elastic fibers and actin in the airways and lung tissue compared with the OVA group $(\mathrm{P}<0.05)$. There were no differences among the OVA-RHO, OVA-C and ORC groups $(\mathrm{P}<0.05)$.

There was an increase in the number of TGF- $\beta$-positive cells in the airways and lung tissue from the OVA group compared with the SAL group $(\mathrm{P}<0.001)$. The OVARHO, OVA-C and ORC groups had reduced numbers of TGF- $\beta$-positive cells in the airways and lung tissue compared with the OVA group $(\mathrm{P}<0.05)$.

The number of MMP-9-positive cells is shown in Table 2. There was an increase in the number of MMP-9positive cells in the airways and lung tissue from the OVA group compared with the SAL group $(\mathrm{P}<0.001)$. The OVA-RHO, OVA-C and ORC groups had reduced numbers of MMP-9-positive cells in the airways and lung tissue compared with the OVA group $(\mathrm{P}<0.001)$.

There was an increase in the number of TIMP-1positive cells in the airways and lung tissue from the OVA group compared with the SAL group $(\mathrm{P}<0.05)$. The OVA-RHO, OVA-C and ORC groups had reduced numbers of TIMP-1-positive cells in the airways and lung tissue compared with the OVA group $(\mathrm{P}<0.05)$. There was a reduction in the number of TIMP-1 positive cells in the ORC group compared to the OVA-RHO and OVA-C groups, but only in the lung tissue $(\mathrm{P}<0.05)$.

Representative photomicrographs of the airways of the animals stained with Picrosirius for collagen content, 


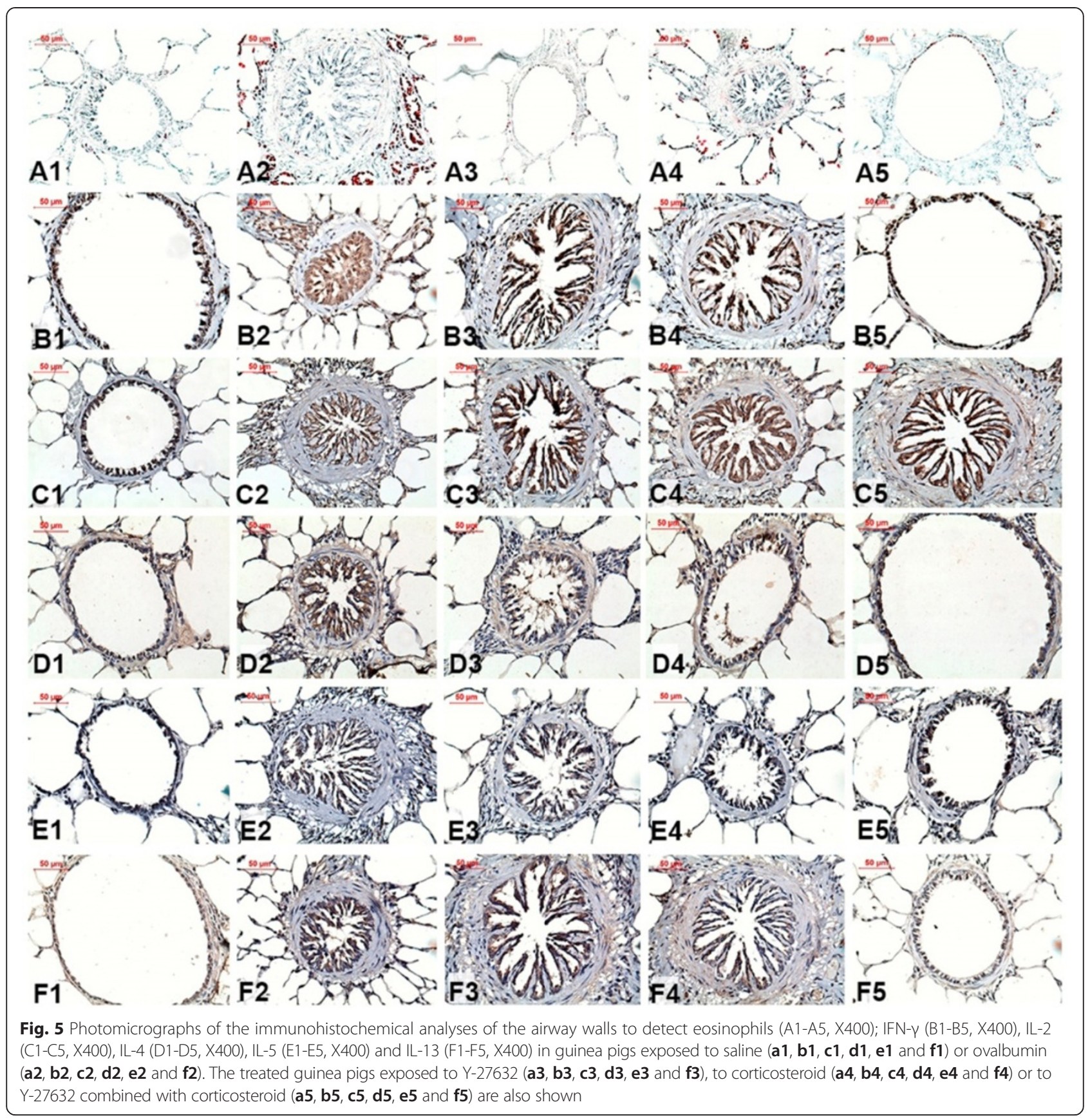

Weighert Resorcin-Fuchsin for elastic fiber content, and immunohistochemical staining for actin, TGF- $\beta$, MMP-9, TIMP-1 detection are shown in Fig. 6.

\section{Effects on oxidative stress and NF-KB expression}

The absolute values of the oxidative stress and nuclear factor markers, including the number of iNOS-positive cells, the volume fraction of 8-iso-PGF2 $\alpha$ and the number of NF-kB-positive cells in the four experimental groups, are shown in Table 3 (airway and lung tissue).
The number of iNOS-positive cells in the airway and lung tissue was significantly higher in the OVA group compared with the SAL group $(\mathrm{P}<0.001)$. The OVA-RHO, OVA-C and ORC groups had reduced numbers of iNOS-positive cells in the airways and lung tissue compared with the OVA group $(\mathrm{P}<0.05)$.

The volume fraction of 8 -iso-PGF $\alpha$ in the airway and lung tissue was significantly higher in the OVA group compared with the SAL group $(\mathrm{P}<0.001)$. The OVARHO, OVA-C and ORC groups had a reduction in the volume fraction of 8 -iso-PGF $2 \alpha$ in the airways and lung 
Table 2 Absolute values of the morphometric analysis for remodeling markers in the airway and lung tissue

\begin{tabular}{|c|c|c|c|c|c|}
\hline \multicolumn{6}{|l|}{ AIRWAY } \\
\hline BIOMARKERS & $\operatorname{SAL}(n=8)$ & OVA $(n=8)$ & OVA-RHO $(n=8)$ & OVA-C $(n=8)$ & ORC $(n=8)$ \\
\hline Collagen Fibers & $9.13 \pm 0.36$ & $25.54 \pm 1.95^{* * *}$ & $15.95 \pm 0.94$ * & $19.60 \pm 1.89 *$ & $10.31 \pm 0.97^{*} / * *$ \\
\hline Elastic Fibers & $2.26 \pm 0.43$ & $17.68 \pm 2.47^{* * *}$ & $4.53 \pm 0.59$ * & $9.33 \pm 0.67 *$ & $4.87 \pm 0.52 *$ \\
\hline Actin & $6.94 \pm 0.67$ & $25.59 \pm 2.26 * * *$ & $12.16 \pm 1.25 *$ & $19.97 \pm 0.94$ * & $15.30 \pm 1.23 *$ \\
\hline TGF- $\beta$ & $4.48 \pm 0.53$ & $13.47 \pm 1.74 * * *$ & $5.35 \pm 1.78 *$ & $7.73 \pm 1.58 *$ & $5.67 \pm 0.91 *$ \\
\hline MMP-9 & $12.35 \pm 0.78$ & $26.48 \pm 1.48 * * *$ & $11.29 \pm 1.38^{+}$ & $13.36 \pm 0.49^{+}$ & $10.82 \pm 1.34^{+}$ \\
\hline TIMP-1 & $4.63 \pm 1.25$ & $17.17 \pm 1.36^{* * *}$ & $8.13 \pm 0.73 *$ & $9.82 \pm 1.27 *$ & $7.30 \pm 0.98 *$ \\
\hline \multicolumn{6}{|l|}{ LUNG TISSUE } \\
\hline BIOMARKERS & $\operatorname{SAL}(n=8)$ & OVA $(n=8)$ & OVA-RHO $(n=8)$ & OVA-C $(n=8)$ & ORC $(n=8)$ \\
\hline Collagen Fibers & $8.62 \pm 0.28$ & $22.42 \pm 0.68 * * *$ & $9.74 \pm 0.64 *$ & $13.76 \pm 0.32$ * & $12.35 \pm 1.73 *$ \\
\hline Elastic Fibers & $7.74 \pm 0.69$ & $19.49 \pm 0.52 * * *$ & $12.93 \pm 1.37 *$ & $12.85 \pm 0.51 *$ & $8.05 \pm 1.59 *$ \\
\hline Actin & $4.52 \pm 0.98$ & $13.24 \pm 0.74$ *** & $4.65 \pm 0.85 *$ & $4.86 \pm 0.84$ * & $4.94 \pm 0.90 *$ \\
\hline TGF- $\beta$ & $5.90 \pm 0.63$ & $15.24 \pm 0.36 * * *$ & $6.37 \pm 0.69 *$ & $6.46 \pm 1.13 *$ & $5.69 \pm 0.74 *$ \\
\hline MMP-9 & $12.53 \pm 0.95$ & $27.17 \pm 0.35^{* * *}$ & $14.53 \pm 0.55^{+}$ & $14.92 \pm 0.81^{+}$ & $13.55 \pm 0.56^{+}$ \\
\hline TIMP-1 & $3.95 \pm 0.74$ & $17.19 \pm 1.12^{* * *}$ & $12.58 \pm 0.59 *$ & $12.18 \pm 1.27 *$ & $8.32 \pm 1.12 * / * *$ \\
\hline
\end{tabular}

The collagen fibers, elastic fibers and actin are expressed in percentage of increase (\%).The TGF- $\beta$, MMP-9 and TIMP- 1 are expressed in positive cells $/ 10^{4} \mu \mathrm{m}^{2}$. ${ }^{* * *} \mathrm{P}<0.001$, compared with the SAL group; ${ }^{*} \mathrm{P}<0.05$, compared with the OVA group; ${ }^{*} \mathrm{P}<0.05$, compared with the OVA-C group, ${ }^{+} \mathrm{P}<0.001$, compared with the OVA group, ${ }^{* * P}<0.05$, compared with the OVA-RHO and OVA-C groups

tissue compared with the OVA group $(\mathrm{P}<0.05)$. There was also a reduction in 8 -iso-PGF2 $\alpha$ in the ORC group compared with the OVA-RHO and OVA-C groups, but only in the lung tissue $(\mathrm{P}<0.05)$.

The number of NF- $\mathrm{kB}$-positive cells in the airway and lung tissue was significantly higher in the OVA group compared with the SAL group $(\mathrm{P}<0.001)$. The OVARHO, OVA-C and ORC groups had reduced numbers of NF-kB-positive cells in the airways and lung tissue compared with the OVA group $(\mathrm{P}<0.05)$. There was also a reduction in NF- $\kappa B$-positive cells in the ORC group compared with the OVA-RHO and OVA-C groups, but only in the lung tissue $(\mathrm{P}<0.05)$.

Representative photomicrographs of the immunohistochemical staining for iNOS, 8-iso-PGF2 $\alpha$ and NF-kB in the airways of the all experimental groups are shown in Fig. 7.

\section{Passive Cutaneous Anaphylaxis (PCA)}

The specific antibody titration of IgG1 in the OVA animals was 1:640. However, the sensitized animals treated with the corticosteroid, the Rho-kinase inhibitor or both had lower levels of the specific IgG1 in the OVA-RHO group (1:160), the OVA-C group (1:160) and the ORC group (1:20). None of the groups had a PCA reaction to the specific IgE at any dilution of antiserum.

\section{Discussion}

In the present study, we evaluated the effects of treatment with the Rho-kinase inhibitor Y-27632, the corticosteroid dexamethasone, or both, on guinea pigs with chronic allergic inflammation. Our analysis focused on the mechanical responses, inflammation, remodeling, and production of oxidative stress in the airways and lung parenchyma. The final results showed that both of the individual treatments were effective in reducing the maximum resistance and elastance of the respiratory system and lung parenchyma when challenged with antigen, suggesting that Rho-kinase inhibition or corticosteroid treatment modulate the constriction of the airways and lung parenchyma. There was also a reduction in $\mathrm{E}_{\mathrm{NO}}$, eosinophilic infiltration, Th1/Th2 inflammatory cytokines, extracellular matrix remodeling, actin content, the number of NF-kB-positive cells and oxidative stress.

The combination of the Rho-kinase inhibitor with the corticosteroid decreased all of the functional and histological parameters to the same extent as the individual treatments, in addition to maximizing the reduction of collagen and IFN- $\gamma$ in the airways, the number of cells positive for IL-2, IFN- $\gamma, \mathrm{NF}-\mathrm{kB}$ and the volume fraction of 8 -iso-PGF $2 \alpha$ in the distal lung tissue.

In the lung parenchyma, the combined treatment of $\mathrm{Y}$ 27632 with the corticosteroid maximized the reduction in the eosinophil counts and TIMP-1-positive cells when compared to animals treated only with the corticosteroid.

Notably, no previous studies have examined repeated treatment with a Rho-kinase inhibitor combined with a corticosteroid as a therapeutic strategy for the control of hyperresponsiveness, remodeling and inflammatory alterations induced by chronic allergic inflammation in the airways and distal lung tissue. 


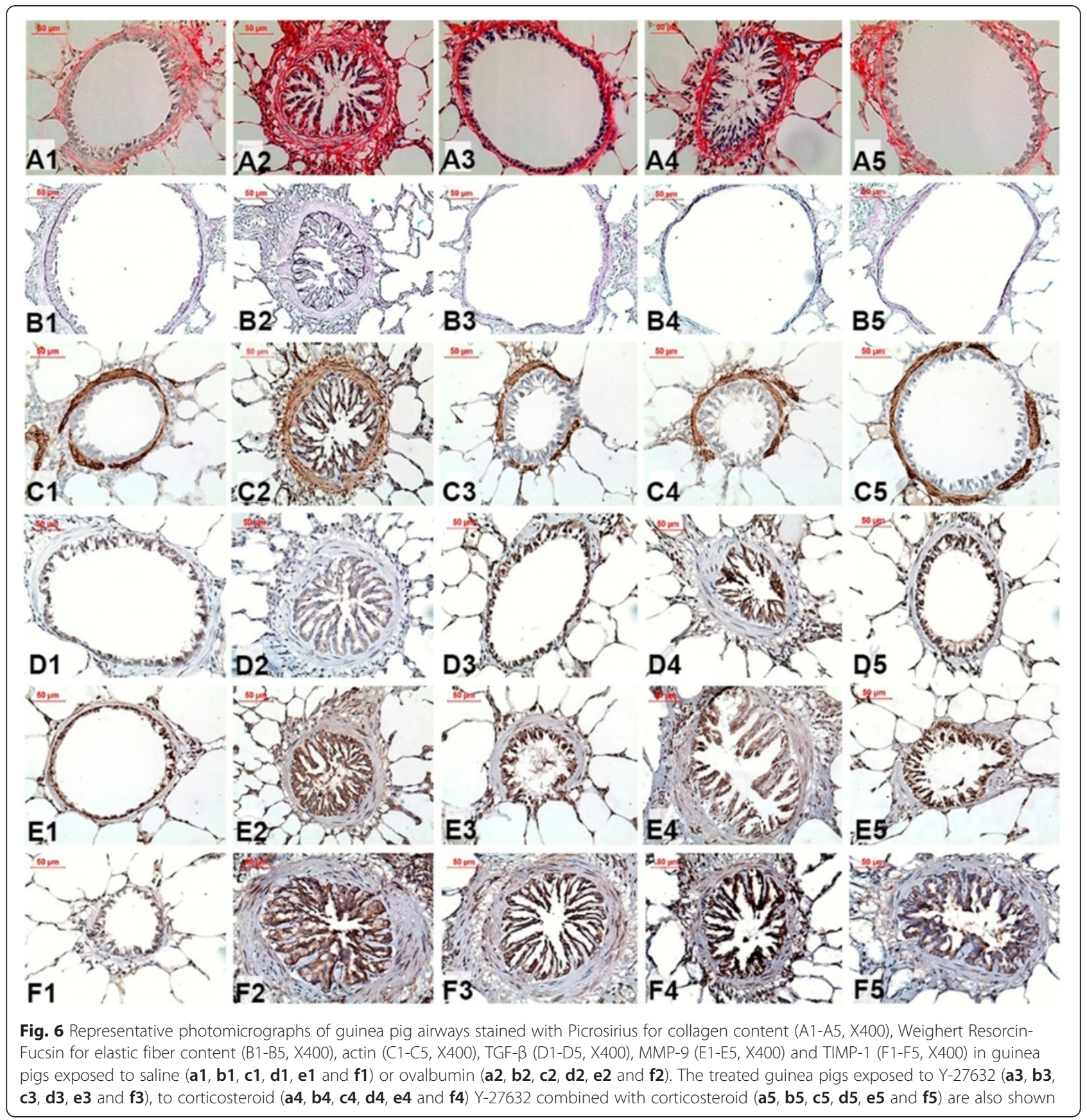

To avoid interfering with the animals' sensitization, we started treatment with the corticosteroid and/or Y-27632 twenty-four hours after the fourth ovalbumin inhalation exposure. Using the PCA technique, we found that the sensitized animals had an increase in specific IgG1 anaphylactic antibodies.

The inhalation time was recorded to evaluate the acute responses to antigen exposure, as previously described [51]. Treatment with the Rho-kinase inhibitor, the corticosteroid or the combination of these therapies attenuated the acute response in sensitized animals. The use of Y-27632 alone increased the contact time with the antigen when compared to the corticosteroid-treated group in sensitized animals. This most likely occurred because of the muscle-relaxing action of the Rho-kinase inhibitor (Y-27632) on the airway smooth muscle [46] and on the myocontractile elements of the lung parenchyma, resulting in diminished signs of respiratory distress and increased inhalation time. On the other hand, dexamethasone affects mainly the inflammatory component of asthma. 
Table 3 Absolute values of the morphometric analysis for oxidative stress and transcription factor markers in the airway and lung tissue

\begin{tabular}{|c|c|c|c|c|c|}
\hline \multicolumn{6}{|l|}{ AIRWAY } \\
\hline BIOMARKERS & $\operatorname{SAL}(n=8)$ & OVA $(n=8)$ & OVA-RHO $(n=8)$ & OVA-C $(n=8)$ & $\mathrm{ORC}(\mathrm{n}=8)$ \\
\hline iNOS & $5.46 \pm 0.17$ & $17.44 \pm 1.47^{* * *}$ & $7.47 \pm 0.85 *$ & $10.20 \pm 2.12 *$ & $9.70 \pm 0.81 *$ \\
\hline 8-iso-PGF2a & $11.25 \pm 0.38$ & $26.47 \pm 1.28 * * *$ & $14.48 \pm 2.97 *$ & $15.26 \pm 1.37 *$ & $13.28 \pm 1.16 *$ \\
\hline$N F-K B$ & $6.18 \pm 0.48$ & $17.36 \pm 1.46^{* * *}$ & $7.69 \pm 0.42 *$ & $7.29 \pm 1.34 *$ & $5.35 \pm 0.89 *$ \\
\hline \multicolumn{6}{|l|}{ LUNG TISSUE } \\
\hline BIOMARKERS & $\operatorname{SAL}(\mathrm{n}=8)$ & OVA $(n=8)$ & OVA-RHO $(n=8)$ & OVA-C $(n=8)$ & ORC $(n=8)$ \\
\hline iNOS & $1.26 \pm 0.37$ & $10.14 \pm 0.38 * * *$ & $4.37 \pm 0.85 *$ & $5.42 \pm 0.94$ * & $4.67 \pm 0.37$ * \\
\hline 8-iso-PGF2a & $1.15 \pm 0.38$ & $18.84 \pm 1.85 * * *$ & $9.48 \pm 0.85 *$ & $10.14 \pm 0.73 *$ & $2.18 \pm 0.54 * / * *$ \\
\hline$N F-k B$ & $1.38 \pm 0.31$ & $18.37 \pm 1.78$ *** & $11.37 \pm 1.63 *$ & $10.88 \pm 0.96 *$ & $5.70 \pm 0.94 * / * *$ \\
\hline
\end{tabular}

The iNOS and NF-KB are expressed in positive cells $/ 10^{4} \mu \mathrm{m}^{2}$. The 8-iso-PGF2 $\alpha$ is expressed in percentage of increase (\%). ${ }^{* * *} \mathrm{P}<0.001$, compared with the SAL group; ${ }^{*} \mathrm{P}<0.05$, compared with the OVA group; ${ }^{*} \mathrm{P}<0.05$, compared with the OVA-RHO and OVA-C groups

We believe that several mechanisms contributing to the acute responses to antigen challenge, including smooth muscle contraction, were most likely altered by treatment with Y-27632 and the protective effect of the corticosteroid $[25,36]$.

As a confirmation that these three treatments (separate use of Y-27632 and the corticosteroid, and the combined use of the corticosteroid with Y-27632) can effectively control the inflammatory process, we observed a significant reduction in $\mathrm{E}_{\mathrm{NO}}$ among the animals sensitized with ovalbumin.

The $\mathrm{E}_{\mathrm{NO}}$ level has been proposed as an indirect marker of lung inflammation and correlates with the severity and response to the treatments. It is also elevated in asthmatics and animal models of chronic pulmonary inflammation $[2,25,36]$. Nitric oxide is involved in various mechanisms of asthma physiopathology. Previous studies have demonstrated that nitric oxide derived from constitutive isoforms has protective effects on bronchoconstriction and remodeling [37], whereas nitric oxide produced by iNOS is involved in the constriction, inflammation and remodeling processes [38, 49].

The maximum elastance and resistance responses after antigen challenge decreased in both the respiratory system and the distal pulmonary tissue when the sensitized

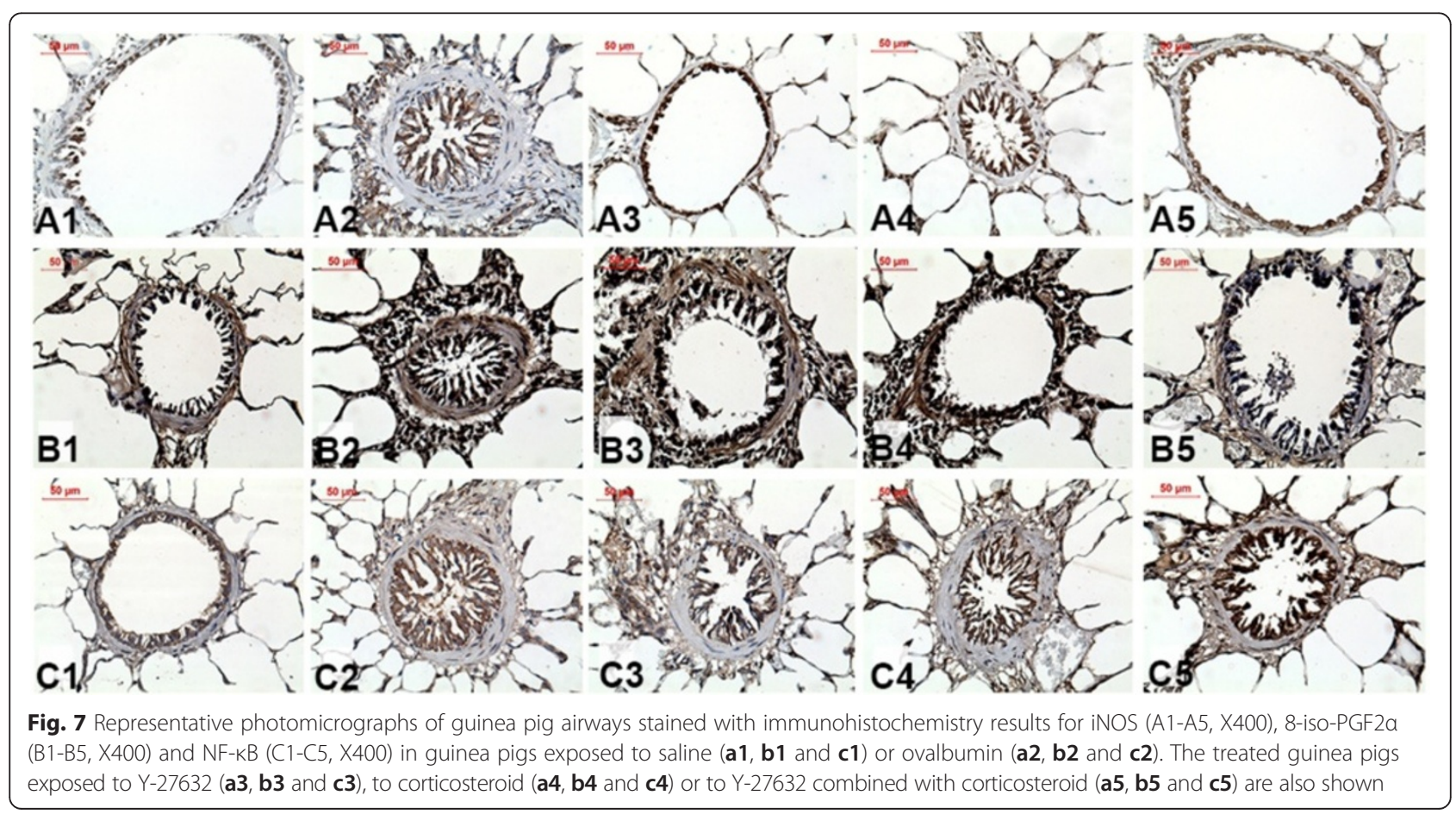


animals were treated with Y-27632, the corticosteroid, or a combination of both treatments, compared to the animals that received the vehicle. To further investigate the mechanisms involved in the control of the mechanical responses, we evaluated the volume fraction of actin in the airways and in the lung parenchyma of sensitized and treated guinea pigs. There was a decrease in the volume fraction of actin in the airway walls and alveolar septa in the treated groups compared to the untreated groups.

The results from different studies using the same model of experimental asthma have shown that treatment with Y-27632 is effective in decreasing the actin content in the airways [36] and in the distal parenchyma [41], but none of the studies assessed the effects of this inhibitor combined with corticosteroids. In the current study, the Rho-kinase inhibitor, alone or in combination with a corticosteroid, was able to reduce the volume fraction of actin compared to the OVA group.

There is evidence that activated Rho-kinase regulates actin/myosin contractibility regardless of the level of free calcium [31]. Actin is part of the cytoskeleton of endothelial cells, and the presence of inflammatory agonists increases cytosolic calcium levels. Increased calcium levels diminish cAMP and activate RhoA/Rho-kinase, causing the reorganization of the cortical actin into stress fibers, which are bundles of actin/myosin necessary to induce cell contraction [39]. In the distal parenchyma, the actin is localized in the myocontractile elements, such as myofibroblasts.

Corticosteroids may directly or indirectly modulate the contraction of the airway smooth muscle by suppressing the agonistic responses induced by an increase in intracellular calcium or by down-regulation linked to uncoupling receptors $\left(\mathrm{M}_{2}\right.$ or $\mathrm{M}_{3}$ muscarinic, $\mathrm{H}_{1}$ histaminic receptors). In addition, corticosteroids can enhance the relaxation of the airway smooth muscle by activating AMP cycledependent or -independent mechanisms. The effects of dexamethasone on human airway smooth muscle were studied by Goldsmith et al. [10]. These authors showed that in human bronchial cells, corticosteroids reduced the level of smooth muscle- $\alpha$ and that such effects were mediated, at least in part, by the attenuation of mRNA translation and increased protein degradation.

The combined treatments resulted in a reduction in the number of cells positive for IFN- $\gamma$ in the airways and in the lung parenchyma. We also observed a greater reduction in eosinophils and IL-2 in the lung parenchyma when both treatments were combined. Additionally, our results showed that in the lung parenchyma, treatment with the Rho-kinase inhibitor had a greater impact on reducing the eosinophil counts than treatment with the corticosteroid, showing that use of this drug by itself is promising.

In a related study, Souza et al. [48] investigated the effects of the corticosteroid montelukast and $1400 \mathrm{~W}$ (a selective iNOS inhibitor) in the peripheral lung tissue of guinea pigs with chronic allergic pulmonary inflammation. The results showed that the isolated use of dexamethasone was able to reduce the eosinophilic infiltrates and the number of Th1 (IFN- $\gamma$ ) and Th2 (IL-4 and IL-5) cells. Hence, the combination of an iNOS inhibitor and montelukast caused a maximized reduction in IL-4, IL-5, and IFN- $\gamma$. In mice chronically exposed to ovalbumin, chronic administration of budesonide reduced airway hyperresponsiveness, as well as leukocyte infiltration, with a decrease in the production of Th2 mediators such as IL-4, IL-12, and eotaxin-1 [28].

The results of the present study corroborated data in the literature describing the effect of a Rho-kinase inhibitor on eosinophil recruitment. Taki et al. [50] observed that the Rho-kinase inhibitor Fasudil reduced the number of eosinophils after allergen challenge, although it did not affect the recruitment of other inflammatory cells. Hashimoto et al. [14] demonstrated that the Rhokinase inhibitor Y-27632 had a key role in reducing the infiltration and activation of inflammatory cells.

When we evaluated the alterations of the extracellular matrix, particularly the volume fraction of collagen and elastic fibers and the numbers of TIMP-1, MMP-9 and TGF- $\beta$ positive cells, we observed a reduction in the airway and distal lung parenchyma of the sensitized animals treated with the Rho-kinase inhibitor or with the corticosteroid. The combination of the corticosteroid with Y-27632 enhanced the reduction in the volume fraction of collagen fibers present in the airways. We also observed a greater attenuation of TIMP-1-positive cells in the lung parenchyma when both drugs were combined.

These results can be explained, at least in part, by the reduction in eosinophil recruitment and Th1/Th2 inflammatory cytokine levels, as demonstrated by the correlation data.

Studies suggest the importance of Rho-kinase modulation in the remodeling process. Zhou et al. [54] showed that Rho-kinase activation is crucial to collagen synthesis, which may be related to a combination of factors including the inhibition of the c-Jun $\mathrm{N}$-terminal kinase (JNK) and TGF- $ß$ pathways. Additionally, Kondrikov et al. [22] concluded that oxygen toxicity induces ROS to separate the guanine nucleotide dissociation inhibitor (GDI, a regulator of Rho GTPase activity) from Rhokinase, leading to the activation of the Rho-kinase pathway and contributing to an increase in type I collagen synthesis.

Other studies suggest that inhaled corticosteroids are unable to reduce the pulmonary remodeling responses completely [16, 48]. In this regard, Goleva et al. [11] showed that in asthmatics resistant to steroid treatment, there was an MMP-9/TIMP-1 imbalance that promoted 
proteolysis and contributed to the chronic remodeling of the airways and the non-reversibility of the bronchial smooth muscle contraction.

Chakir et al. [3] studied bronchial biopsies of patients with moderate and severe asthma treated with oral corticosteroids for two weeks. They showed that this treatment was unable to reduce type I and II collagen or TGF- 3 . In contrast, the administration of beclomethasone in daily doses of $800 \mathrm{mg}$ diminished the deposition of collagen in patients with asthma [16]. Miller et al. [30] demonstrated that corticosteroids inhibit TGF beta1 expression in eosinophils and macrophages. McMillan et al. [28] demonstrated in mice chronically exposed to ovalbumin that budesonide was able to reduce collagen deposition and mucus production by regulating inflammation and TGF beta1 signaling rather than by decreasing TGF beta protein production.

Our evaluation of the importance of oxidative stress also demonstrated an attenuation of the number of iNOSpositive cells and the volume fraction of 8 -iso-PGF2 $\alpha$ in sensitized animals treated solely with the Rho-kinase inhibitor Y-27632 or with the corticosteroid. When the treatments were combined, all of these parameters diminished, but there was a greater reduction in 8 -iso-PGF2 $\alpha$ in the distal pulmonary tissue.

It has been clearly demonstrated that iNOS activation contributes to the promotion of peroxynitrite production, which leads to lipid peroxidation and isoprostane (8-iso-PGF2 $\alpha$ ) generation [31]. The isoprostanes contribute to smooth muscle contraction by acting through the tyrosine kinases and Rho/Rho-kinase, leading to the decreased activity of myosin light-chain phosphatase and increasing the level of phosphorylated myosin lightchain and contraction [19].

McGown et al. [27] demonstrated that Fasudil reduced LPS-induced iNOS superregulation, reducing microvascular inflammation. Jiang and George [20] demonstrated that Rho-kinase inhibition with Y-27632 prevented the reduction of NO induced by TGF- $\beta 2$, thus avoiding iNOS inhibition, and suggesting that TGF- $\beta 2$ inhibits iNOS expression via a Rho-kinase-dependent pathway in pulmonary epithelial cells.

We observed that the cellular expression of NF- $\mathrm{kB}$ was reduced in animals treated with the Rho-kinase inhibitor or with the corticosteroid in sensitized animals. The combination of these treatments allowed for a maximized reduction of NF-kB in the distal pulmonary tissue.

The reduction of NF-kB-induced transcription might result in an inhibition of RhoA upregulation induced by IL-13 and TNF- $\alpha$. Meyer-Schwesinger et al. [30] observed that Rho-kinase inhibition attenuated NF- $\mathrm{BB}$ expression, resulting in protection against injury. These data suggest that NF- $\mathrm{kB}$ expression may also be Rhokinase-dependent.

\section{Conclusions}

The data suggest that Rho-kinase inhibition or treatment with corticosteroids can control the pulmonary mechanical response, Th1 and Th2 lymphocyte and eosinophil responses, extracellular matrix remodeling, and the production of oxidative stress in the airways and distal parenchyma in this animal model. Combined treatment with the Rho-kinase inhibitor and the corticosteroid maximized the control of the remodeling response and inflammation in the airways and parenchyma. Rhokinase inhibition alone or in combination with corticosteroids can be considered a future pharmacological tool for the treatment of chronic pulmonary diseases.

\section{Abbreviations}

AMP: Adenosine monophosphate; AW: Alveolar wall; BWW: Blood vessel wall; BW: Bronchial wall; cAMP: Cyclic adenosine monophosphate; $\mathrm{Ca}^{2+}$ : Ion calcium; $\mathrm{E}_{\mathrm{NO}}$ : Exhaled nitric oxide; Ers: Elastance of respiratory system; Et: Lung tissue elastance; IFN-Y: Interferon gamma; IgE: Immunoglobulin E; IgG1: Immunoglobulin G1; IL: Interleukin; iNOS: Inducible nitric oxide synthase; LPS: Lipopolysaccharide; MMP: Matrix metalloproteinase; mRNA: Messenger RNA; NF-kB: Nuclear factor kappa B; NO: Nitric oxide; ORC: Animals that received ovalbumin, Y-27632 after the fifth inhalation, and corticosteroid treatment; OVA: Animals that received ovalbumin; OVA-C: Animals that received ovalbumin and corticosteroids; OVA-RHO: Animals that received ovalbumin and Y-27632 after the fifth inhalation exposure; PCA: Passive cutaneous anaphylaxis technique; ROS: Reactive oxygen species; Rrs: Resistance of respiratory system; Rt: Lung tissue resistance; SAL: Animals that received normal saline; TGF- $\beta$ : Transforming growth factor beta; Th: T helper; TIMP-1: Tissue inhibitor of metalloproteinases-1; Y-27632: (a pyridine derivative, (+)-(R)-trans-4-(1-aminoethyl)-N-(4-pyridyl) cyclohexane carboxamide); 8-iso-PGF2a: 8-iso-prostaglandin F2alpha.

\section{Competing interests}

The authors declare that they have no competing interests.

\section{Authors' contributions}

PAP designed and performed the major part of the experiments and the morphometric analysis, performed the statistical analysis and drafted the manuscript. RFR, SSP, BMSR, ASAS, DGX, and MAA assisted in performing the experiments. APDR participated in some of the experiments and contributed to the morphometric analysis. CMP, EAL, PRMR, and MAM participated in the design of the study. IFLCT supervised the study, participated in its design, and interpreted the results, as well as prepared the manuscript. All authors have read and approved the final manuscript.

\section{Acknowledgements}

We thank Fundação de Amparo à Pesquisa do Estado de São Paulo (FAPESP) for their financial support. We would like to thank Patrícia Rieken Macedo Rocco (University Federal of Rio de Janeiro) and Darci Delatorre Monfriato (Methodist University of Piracicaba) for contributing space for part of the experiments. We would also like to thank Barbara Oliveira Xavier, Sandra de Moraes Fernezlian, and Esmeralda Meristene for their skillful technical assistance.

\section{Author details}

${ }^{1}$ Department of Medicine, School of Medicine, University of São Paulo, São Paulo, Brazil. 'Laboratory of Pulmonary Investigation, Carlos Chagas Filho Institute of Biophysics, Ilha do Fundão, Federal University of Rio de Janeiro, Rio de Janeiro, Brazil. ${ }^{3}$ Department of Medicine, Laboratory of Experimental Therapeutics, LIM-20, School of Medicine, University of São Paulo, São Paulo, Brazil. ${ }^{4}$ University City of São Paulo (UNICID), São Paulo, Brazil. ${ }^{5}$ Institute of Medical Assistance to the State Public Servant of São Paulo (IAMSPE), São Paulo, Brazil. 
Received: 27 August 2014 Accepted: 6 July 2015 Published online: 12 August 2015

\section{References}

1. Angeli P, Prado CM, Xisto DG, Silva PL, Pássaro CP, Nakazato HD, et al. Effects of chronic L-NAME treatment lung tissue mechanics, eosinophilic and extracellular matrix responses induced by chronic pulmonary inflammation. Am J Physiol Lung Cell Mol Physiol. 2008;294:1197-205.

2. Bukstein D, Luskin AT, Brooks EA. Exhaled nitric oxide as a tool in managing and monitoring difficult-to-treat asthma. Allergy Asthma Proc. 2011;32:185-92.

3. Chakir J, Shannon J, Molet S, Fukakusa M, Elias J, Laviolette M, et al. Airway remodeling-associated mediators in moderate to severe asthma: effect of steroids on TGF-beta, IL-11, IL-17, and type I and type III collagen expression. J Allergy Clin Immunol. 2003;111:1293-8.

4. Davies DE, Wicks J, Powell RM, Puddicombe SM, Holgate ST. Airway remodeling in asthma: new insights. J Allergy Clin Immunol. 2003;111:215-25.

5. Dolhnikoff M, Morin J, Ludwig MS. Human lung parenchyma responds to contractile stimulation. Am J Respir Crit Care Med. 1998;158:1607-12.

6. Doussau F, Gasman S, Humeau Y, Vitiello F, Popoff M, Boquet P, et al. A Rho-related GTPase is involved in $\mathrm{Ca}(2+)$-dependent neurotransmitter exocytosis. J Biol Chem. 2000;275:7764-70

7. Fernández AT, Muñoz Cano RM. Importancia clínica de la afectación de la vía aérea pequeña en el asma. Arch Bronconeumol. 2011;47 Suppl 2:17-9.

8. Fredberg JJ, Stamenovic D. On the imperfect elasticity of lung tissue. J Appl Physiol. 1989;67:2408-19.

9. Global Initiative for Asthma (GINA). http://www.ginasthma.org/documents/4 Accessed 20 Jan 2014

10. Goldsmith AM, Hershenson MB, Wolbert MP, Bentley JK. Regulation of airway smooth muscle alpha-actin expression by glucocorticoids. Am J Physiol Lung Cell Mol Physiol. 2007;292:99-106.

11. Goleva E, Hauk PJ, Boguniewicz J, Martin RJ, Leung DY. Airway remodeling and lack of bronchodilator response in steroid-resistant asthma. J Allergy Clin Immunol. 2007;120:1065-72.

12. Gosens R, Schaafsma D, Grootte Bromhaar MM, Vrugt B, Zaagsma J, Meurs $H$, et al. Growth factor-induced contraction of human bronchial smooth muscle is Rho-kinase-dependent. Eur J Pharmacol. 2004;494:73-6.

13. Hamid Q. Pathogenesis of small airways in asthma. Respiration. 2012;84:4-11.

14. Hashimoto K, Peebles Jr RS, Sheller JR, Jarzecka K, Furlong J, Mitchell DB, et al. Suppression of airway hyperresponsiveness induced by ovalbumin sensitisation and RSV infection with Y-27632, a Rho kinase inhibitor. Thorax. 2002;57:524-7.

15. Hirano K, Derkach DN, Hirano M, Nishimura J, Kanaide H. Protein kinase network in the regulation of phosphorylation and desphosphorylation of smooth muscle myosin light chain. Mol Cell Biochem. 2003;248:105-14.

16. Hoshino M, Takahashi M, Takai Y, Sim J. Inhaled corticosteroids decrease subepithelial collagen deposition by modulation of the balance between matrix metalloproteinase-9 and tissue inhibitor of metalloproteinase-1 expression in asthma. J Allergy Clin Immunol. 1999;104:356-63.

17. lizuka K, Shimizy Y, Tsukagoshi H, Yoshii A, Harada T, Dobashi K, et al. Evaluation of $Y$-27632, a rho-kinase inhibitor, as a bronchodilator in guinea pigs. Eur J Pharmacol. 2000;406:273-79.

18. Ito K, Chung KF, Adcock IM. Uptade on glucocorticoid action and resistance. J Allergy Clin Immunol. 2006;117:522-43.

19. Janssen LJ, Premji M, Netherton S, Coruzzi J, Lu-Chao H, Cox PG. Vasoconstrictor actions of isoprostanes via tyrosine kinase and Rho kinase in human and canine pulmonary vascular smooth muscles. Br J Pharmacol. 2001;132:127-34.

20. Jiang J, George SC. TGF- $\beta 2$ reduces nitric oxide synthase mRNA through a ROCK-dependent pathway in airway epithelial cells. Am J Physiol Lung Cell Mol Physiol. 2011;301:361-7.

21. Kitazawa T, Masuo M, Somlyo AP. G protein-mediated inhibition of myosin light-chain phosphatase in vascular smooth muscle. Proc Natl Acad Sci. 1991;88:9307-10

22. Kondrikov D, Caldwell RB, Dong Z, Su Y. Reactive oxygen species-dependent RhoA activation mediates collagen synthesis in hyperoxic lung fibrosis. Free Radic Biol Med. 2011;50:1689-98.
23. Kraft M, Part III. Location of asthma inflammation and the distal airways: clinical implications. Curr Med Res Opin. 2007;23 Suppl 3:21-7.

24. Lanças T, Kasahara DI, Prado CM, Tibério IF, Martins MA, Dolhnikoff M. Comparison of early and late responses to antigen of sensitized guinea pig parenchymal lung strips. J Appl Physiol. 2006;100:1610-6.

25. Leick-Maldonado EA, Kay FU, Leonhardt MC, Kasahara DI, Prado CM, Fernandes FT, et al. Comparison of glucocorticoid and cysteinyl leukotriene receptor antagonist treatments in an experimental model of chronic airway inflammation in guinea-pigs. Clin Exp Allergy. 2004;34:145-52.

26. Matsumoto H, Moir LM, Oliver BG, Burgess JK, Roth M, Black JL, et al. Comparison of gel contraction mediated by airway smooth muscle cells from patients with and without asthma. Thorax. 2007;62:848-54.

27. McGown CC, Brown NJ, Hellewell PG, Brookes ZL. ROCK induced inflammation of the microcirculation during endotoxemia mediated by nitric oxide synthase. Microvasc Res. 2011;81:281-8.

28. McMillan SJ, Xanthou G, Lloyd CM. Therapeutic administration of Budesonide ameliorates allergen-induced airway remodelling. Clin Exp Allergy. 2005;35:388-96.

29. Meyer-Schwesinger C, Dehde S, von Ruffer C, Gatzemeier S, Klug P, Wenzel $\cup O$, et al. Rho kinase inhibition attenuates LPS-induced rena failure in mice in part by attenuation of NF-kappaB p65 signaling. Am J Physiol Renal Physiol. 2009;296:1088-99.

30. Miller M, Cho JY, McElwain S, Shim JY, Manni M, Baek JS, et al. Corticosteroids prevent myofibroblast accumulation and airway remodeling in mice. Am J Physiol Lung Cell Mol Physiol. 2006:290:162-9

31. Mong PY, Wang Q. Activation of Rho kinase isoforms in lung endothelial cells during inflammation. J Immunol. 2009;182:2385-94.

32. Mota I, Perini A. A heat labile mercaptoethanol susceptible homocytotropic antibody in the guinea pig. Life Sci II. 1970;9:923-30.

33. Mukai Y, Shimokawa H, Matoba T, Kandabashi T, Satoh S, Hiroki J, et al. Involvement of Rho-kinase in hypertensive vascular disease: a novel therapeutic target in hypertension. FASEB J. 2001;1062-64.

34. Nakashima AS, Prado CM, Lanças T, Ruiz VC, Kasahara DI, LeickMaldonado EA, et al. Oral tolerance attenuates changes in in vitro lung tissue mechanics and extracellular matrix remodeling induced by chronic allergic inflammation in guinea pigs. J Appl Physiol. 2008;104:1778-85

35. Pfitzer G. Invited review: regulation of myosin phosphorylation in smooth muscle. J Appl Physiol. 2001;91:497-503.

36. Possa SS, Charafeddine HT, Righetti RF, da Silva PA, Almeida-Reis R, Saraiva-Romanholo BM, et al. Rho-kinase inhibition attenuates airway responsiveness, inflammation, matrix remodeling, and oxidative stress activation induced by chronic inflammation. Am J Physiol Lung Cell Mol Physiol. 2012;303:939-52.

37. Prado CM, Leick-Maldonado EA, Kasahara DI, Capelozzi VL, Martins MA, Tibério IF. Effects of acute and chronic nitric oxide inhibition in an experimental model of chronic pulmonary allergic inflammation in guinea pigs. Am J Physiol Lung Cell Mol Physiol. 2005;289:677-83.

38. Prado CM, Leick-Maldonado EA, Yano L, Leme AS, Capelozzi VL, Martins $M A$, et al. Effects of nitric oxide synthases in chronic allergic airway inflammation and remodeling. Am J Respir Cell Mol Biol. 2006;35:457-65.

39. Prasain N, Stevens T. The actin cytoskeleton in endothelial cell phenotypes. Microvas Res. 2009;77:53-63.

40. Ramos-Barbón D, Parra-Arrondo A. Inflammation and remodeling of the distal airways: studies in humans and experimental models. Arch Bronconeumol. 2011:47 Suppl 2:2-9.

41. Righetti RF, Pigati PA, Possa SS, Habrum FC, Xisto DG, Antunes A, et al. Effects of Rho-kinase inhibition in lung tissue with chronic inflammation. Respir Physiol Neurobiol. 2014;192:134-46.

42. Rocco PR, Negri EM, Kurtz PM, Vasconcellos FP, Silva GH, Capelozzi VL, et al. Lung tissue mechanics and extracellular matrix remodeling in acute lung injury. Am J Respir Crit Care Med. 2001;164:1067-71.

43. Romero PV, Zin WA, Lopez-Aguilar J. Frequency characteristics of lung tissue strip during passive stretch and induced pneumoconstriction. J Appl Physiol. 2001;91:882-90.

44. Ruiz-Schütz VC, Drewiacki T, Nakashima AS, Arantes-Costa FM, Prado CM, Kasahara DI, et al. Oral tolerance attenuates airway inflammation and remodeling in a model of chronic pulmonary allergic inflammation. Respir Physiol Neurobiol. 2009;165:13-21. 
45. Sakurada S, Takuwa N, Sugimoto N, Wang Y, Seto M, Sasaki Y, et al. $\mathrm{Ca} 2+-$ dependent activation of Rho and Rho kinase in membrane despolarization-induced and receptor stimulation-induced vascular smooth muscle contraction. Cir Res. 2003;93:548-56.

46. Schaafsma D, Bos IS, Zuidhof AB, Zaagsma J, Meurs H. Inhalation of the Rho-kinase inhibitor Y-27632 reverses allergen-induced airway hyperresponsiveness after the early and late asthmatic reaction. Respir Res. 2006;7:121.

47. Schaafsma D, Gosens R, Bos IS, Meurs H, Zaagsma J, Nelemans SA. Allergic sensitization enhances the contribution of Rho-kinase to airway smooth muscle contraction. Br J Pharmacol. 2004;143:477-84.

48. Souza FC, Gobbato NB, Maciel RG, Prado CM, Martins MA, Leick EA, et al. Effects of corticosteroid, montelukast and iNOS inhibition on distal lung with chronic inflammation. Respir Physiol Neurobiol. 2013;185:435-45.

49. Starling CM, Prado CM, Leick-Maldonado EA, Lanças T, Reis FG, Aristóteles $L R$, et al. Inducible nitric oxide synthase inhibition attenuates lung tissue responsiveness and remodeling in a model of chronic pulmonary inflammation in guinea pigs. Respir Physiol Neurobiol. 2009;165:185-94.

50. Taki F, Kume H, Kobayashi T, Ohta H, Aratake H, Shimokata K. Effects of Rho-kinase inactivation on eosinophilia and hyper-reactivity in murine airways by allergen challenges. Clin Exp Allergy. 2007;37:599-607.

51. Tibério IF, Turco GM, Leick-Maldonado EA, Sakae RS, Paiva SO, do Patrocinio $M$, et al. Effects of neurokinin depletion on airway inflammation induced by chronic antigen exposure. Am J Respir Crit Care Med. 1997;155:1739-47.

52. Uehata M, Ishizaki T, Satoh H, Ono T, Kawahara T, Morishita T, et al. Calcium sensitization of smooth muscle mediated by a Rho-associated protein kinase in hypertension. Nature. 1997;389:990-4.

53. Weibel ER. The challenge of measuring lung structure. On the "Standards for the Quantitative Assessment of Lung Structure". Nihon Kokyuki Gakkai Zasshi. 2010;48:637-43.

54. Zhou H, Zhang KX, Li YJ, Guo BY, Wang M, Wang M. Fasudil hydrochloride hydrate, a Rho-kinase inhibitor, suppresses high glucose-induce proliferation and collagen synthesis in rat cardiac fibroblasts. Clin Exp Pharmacol Physiol. 2011;38:387-94.

\section{Submit your next manuscript to BioMed Central and take full advantage of:}

- Convenient online submission

- Thorough peer review

- No space constraints or color figure charges

- Immediate publication on acceptance

- Inclusion in PubMed, CAS, Scopus and Google Scholar

- Research which is freely available for redistribution 